\title{
The residential coal consumption: disparity in urban-rural China
}

\section{Jiandong Chen ${ }^{\mathrm{a}}$, Yinyin Wu $\mathrm{W}^{\mathrm{a}}$, Malin Song ${ }^{\mathrm{b},}$, and Yizhe Dongc}

${ }^{\text {a }}$ School of Public Finance and Taxation, Southwestern University of Finance and Economics, Chengdu, 611170, PR China;

b School of Mathematics and Finance, Chuzhou University, Chuzhou, 239000, PR China;

${ }^{\mathrm{c}}$ Business School, Aberdeen University, Aberdeen, AB24 3QY, Scotland UK.

Abstract: Research on China's coal consumption addresses global concerns related to clean energy, sustainable communities, and climate action, among others (i.e., Targets 7, 11, and 13 in the new United Nations Sustainable Development Goals). Most existing literature has focused on industrial coal rather than residential coal consumption. This study analyzed the Chinese urban-rural residential coal consumption disparity during 2000-2015 by the expanded calculating approach of the Gini coefficient combined with the Log Mean Divisia Index (LMDI). Analysis of the urban-rural residential coal consumption disparity and its elasticity to LMDI decomposition effects have not been undertaken in other literature. The empirical results demonstrated that the increased disparity during the study period mainly resulted from the increased ratio of rural to urban coal consumption per capita. Meanwhile, the decreasing per capita urban coal proportion and increasing rural per capita income were the leading factors for their respective coal consumption variations. Furthermore, urban residential coal consumption showed strong decoupling, while rural residential coal consumption showed weak decoupling, and the variation in the urban-rural gap was sensitive to rural energy intensity and population. The study explored the underlying reasons for the increasing disparity and supported the "energy ladder" theory.

\footnotetext{
${ }^{1}$ Corresponding author. E-mail: songmartin@163.com, Tel: +86 15805521822.
} 
Keywords: Residential coal consumption; Urban-rural disparity; Gini coefficient; Log Mean Divisia Index (LMDI).

\section{Introduction}

Coal is the most common source of energy in China (Jafari et al., 2017), accounting for $64 \%$ of its energy consumption in 2015, according to the China Statistical Yearbook (2016). However, since coal is a type of non-renewable natural resource, its supply could be exhausted, while it also emits various pollutants, such as sulfur dioxide, mercury, and coal bottom ash (Mukherjee et al., 2008; Singh and Siddique, 2013). In fact, China's environmental pollution-especially severe air pollution in winter mainly caused by coal burning - has garnered extensive attention in recent years (Sun et al., 2016; Yang and Teng, 2016). As part of the sustainable management of natural resources to serve sustainable development goals, policies for managing coal resources and constraining its consumption have been actively promoted by the Chinese government, especially in the $11^{\text {th }}(2006-2010)$ and $12^{\text {th }}$ (2011-2015) Five-year Plans. Moreover, cutting coal consumption in China contributes to the realization of global sustainable development goals (e.g., with Targets 11.6.2 and 13.2 in the new United Nations Sustainable Development Goals). In academia, China's coal consumption pattern has attracted worldwide attention (Bhattacharya et al., 2015; Zhang et al., 2016), as it is the world's largest developing country. However, extant literature has focused more on aggregate or industrial coal consumption (Song et al., 2016; Li and Hu, 2017), and less on residential coal consumption. The China Energy Statistical Yearbook (2016) revealed that the residential sector was the second-largest coal consumer during 2000-2015, behind only the industrial sector. In addition, research on residential coal consumption is beneficial for the sustainable management of natural resources toward sustainable development goals. Such research would help to decouple the human lives' improvement from resource depletion and environmental degradation.

According to the China Energy Statistical Yearbook (2001-2016), the total residential coal consumption in China has been fluctuating in recent years. While coal 
consumption was 61.45 million tons of coal equivalent (TCE) in 2000, it declined to 69.69 million in 2015, after reaching a peak in 2005 of 80.44 million tons of coal equivalent. However, an analysis of the dual structure in the Chinese urban and rural economies presents a different version of China's residential coal consumption. Urban residential coal consumption has declined significantly since 2004, while rural residential coal consumption followed a fluctuating, but increasing, trend between 2000 and 2015. Furthermore, a significant disparity in China's urban-rural coal consumption was observed. Moreover, since residential coal-fired equipment, mainly in rural areas, was still simple and crude, pollutant emissions due to inefficient combustion of bulk coal not only caused a significant deterioration in local air quality (Geng et al., 2012) but also became one of the most important causes of haze pollution in cities. Therefore, research on China's residential coal consumption should not neglect the consumption disparity between urban and rural regions - this area of analysis has often been neglected by academia.

Residential energy consumption has been part of energy research (Du et al., 2017; Nilsson et al., 2017; Son and Kim, 2017), and many research works have studied the problems of China's residential energy consumption. While analyzing user behavior among rural residents, Zhang et al. (2014) showed that nearly $40 \%$ of rural residents still used bioenergy (crop straws and firewood) for indoor heating and cooking, and bioenergy consumption declined modestly with income growth, increased time required for biomass collection, and less farmland. Similarly, Zhou and Teng (2013) showed that electricity consumption of urban residents in Sichuan Province was both price- and income- inelastic, while the number of home appliances was an important factor affecting household electricity consumption. Given the recent trends in China's urbanization, Sun and Ouyang (2016) explored the "lock-in effect" of household energy consumption patterns from the perspective of price and income elasticities during the process of urbanization, and noted that a rational energy price mechanism was important to ensure sustainable development during the process of urbanization in China. In addition, indirect household energy consumption and its resultant indirect carbon dioxide emissions have been included in some research studies. For example, 
Dai et al. (2012) used the Working-Leser model to predict how China's residential energy consumption mode could affect direct and indirect residential energy demand and corresponding carbon dioxide emissions in the future.

Although a few research works have studied only China's residential coal consumption patterns, existing literature more or less is related to the analysis of residential coal consumption and shows that there is a large urban-rural disparity in residential coal consumption. For example, based on the research of 26 of China's provinces, including 1,450 urban and rural residential samples, Zheng et al. (2014) noted a relatively large disparity between the patterns of urban and rural residential coal consumption, as urban residents seldom used coal while rural residents' coal consumption ratio was $5.65 \%$. Zhao et al. (2012a) analyzed residential energy consumption in the western region of the Loess Plateau in China and showed that direct coal consumption of residents in capital cities, medium-sized cities, counties, and rural areas was $39.8 \mathrm{~kg}, 57.4 \mathrm{~kg}, 183.7 \mathrm{~kg}$, and $851.5 \mathrm{~kg}$ of standard coal, respectively.

Furthermore, in terms of coal consumption, some literature has confirmed the “energy ladder" theory (Hosier and Dowd, 1987; Van Ruijven et al., 2008). The energy ladder is a concept used to describe the transition of households from traditional energy sources to more sophisticated fuels following their improved economic status. As pointed by Hosier and Dowd (1987), the underlying assumption of the energy ladder within the energy systems of developing countries is that households are faced with an array of energy supply choices which can be arranged in order of increasing technological sophistication. At the top of the list is electricity, while the lower end of the range includes fuel wood, dung, and crop wastes. As a household's economic well-being increases, it is assumed to move "up" the energy ladder to more sophisticated energy carriers. If the economic status declines, through either a decrease in income or an increase in fuel prices, the household is expected to move "down" the energy ladder to less sophisticated energy carriers. Thus, the energy ladder serves as a stylized extension of the economic theory of the consumer: as income rises (or falls), households consume not only more (or less) of the same goods, 
but they also shift to consuming higher (or lower) quality goods (Hosier and Dowd, 1987, pp.347-348). Cai and Jiang (2008) pointed out that the energy carriers chosen by residents in Xi'an changed from low-quality bioenergy to high-quality commercial energy with urbanization and the consequent increase in income levels. The poorest villages and richest capital cities hardly consumed coal; consumption was concentrated among residents in medium-sized cities and counties. In addition, based on the energy ladder hypothesis, Niu et al. (2012) found that the characteristics of the ladder were obvious. The authors found that $94.1 \%$ of rural household samples in western China still showed a tendency to use coal stoves for indoor heating in winter, while urban residents scarcely used coal.

Furthermore, as rural residents consume more coal, some literature has focused on rural residential coal consumption. Zhang and Kotani (2012) found that coal consumption per capita in rural areas (Beijing suburbs) had reduced substantially, while increases in per capita income and access to renewable energy technologies reduced residential coal consumption. However, based on a survey of Zibo City in Shandong Province, Liang et al. (2013) showed that the share of non-renewable energy sources (mainly coal) in rural residential consumption had increased from $15.7 \%$ in 1980 to $87.7 \%$ in 2009 . Clearly, difference in sample selection would result in different coal consumption trends among rural residents.

The Gini coefficient is the common index to measure income inequality (Sen, 1997; Lin et al., 2008), and some scholars have applied it to study the disparity in energy consumption (Fernandez et al., 2005; Papathanasopoulou and Jackson, 2009; Sun et al., 2010). With regard to the use of research tools for analyzing energy consumption variation, index decomposition analysis is a common tool (e.g., Fan et al., 2013) in addition to the regression of econometric models (e.g. Auffhammer and Wolfram, 2014). Due to its applicability to theoretical bases, simple operability, interpretability of results, and other desirable characteristics, the Log Mean Divisia Index (LMDI) is a preferred method to decompose factors (Ang, 2004, 2015). For example, Achão and Schaeffer (2009) applied the LMDI method to analyze Brazilian residential electric consumption in terms of activity, intensity, and structure effects. 
Zhao et al. (2012b) applied the LMDI method to investigate the effects of price, structure, expenditure, and population on China's residential energy consumption. Similarly, Nie and Kemp (2014) decomposed not only the regular population and structure effect but also the floor space and appliance effect.

In summary, although there have been many studies on China's coal consumption and residential energy consumption patterns in recent years, this literature has not focused on residential coal consumption. Moreover, owing to non-targeted research and unrepresentative survey samples, this literature cannot clearly reflect the factors affecting China's residential coal consumption changes and the urban-rural disparity. In an attempt to bridge this gap in the literature, this study analyzes the disparity in China's urban-rural coal consumption patterns with an expanded calculating approach of the urban-rural Gini coefficient and a comprehensive LMDI method. Furthermore, previous literature did not analyze the urban-rural residential coal consumption disparity and its elasticity to LMDI decomposition effects. Moreover, our results present the underlying reasons for the widening of this disparity in urban-rural residential coal consumption and support the energy ladder theory.

The rest of the paper is organized as follows. In Section 2, we describe the empirical methods and data. Section 3 presents the empirical results. Finally, Section 4 concludes and offers policy implications.

\section{Material and methods}

\subsection{Urban-rural residential coal consumption Gini coefficient}

Based on the calculation principles of the Lorenz curve and Gini coefficient, this study expands the calculation approach of the urban-rural Gini coefficient by replacing the urban and rural aggregate residential coal consumption $\left(E_{u}\right.$ and $\left.E_{r}\right)$ with the ratio of rural-to-urban per capita coal consumption $(e)$. This further simplifies the analysis of the factors influencing the disparity in urban-rural residential coal consumption. Specifically, in an urban-rural dualistic society (during the years of this study's sample, the proportion of rural residential coal consumption was always 
greater than that of urban residents), the Gini coefficient of urban-rural residential coal consumption $\left(G_{u r}\right)$ can be expressed as

$$
\begin{aligned}
& G_{u r}=P P_{u}-\frac{E_{u}}{E_{u}+E_{r}}=\frac{E_{r}}{E_{u}+E_{r}}-P P_{r} \\
& =\frac{(e-1) \times P P_{u} \times\left(1-P P_{u}\right)}{(e-1) \times\left(1-P P_{u}\right)+1}
\end{aligned}
$$

For further details, refer to the specified derivation in Appendix A.

$G_{u r}, E_{u}, E_{r}$, and $e$ are as denoted previously, and $P P_{u}$ represents the proportion of urban population ${ }^{2}$, or the urbanization rate.

Evidently, the urban-rural coal consumption Gini coefficient was determined jointly by $P P_{u}$ and $e$, and their impacts on urban-rural residential coal consumption disparity were as follows:

$$
\begin{aligned}
& \frac{\partial G_{u r}}{\partial P P_{u}}=\frac{\left[(e-1) \times\left(1-P P_{u}\right)+1\right]^{2}-e}{\left[(e-1) \times\left(1-P P_{u}\right)+1\right]^{2}}(2) \\
& \frac{\partial G_{u r}}{\partial e}=\frac{P P_{u} \times\left(1-P P_{u}\right)}{\left[(e-1) \times\left(1-P P_{u}\right)+1\right]^{2}}(3) \\
& \text { If }\left[(e-1) \times\left(1-P P_{u}\right)+1\right]^{2}-e \succ 0, \text { the promotion of urbanization would enlarge the }
\end{aligned}
$$
urban-rural disparity when $\left[(e-1) \times\left(1-P P_{u}\right)+1\right]^{2}-e=0, P P_{u}$ reaches $P P_{u \max }$ (the corresponding urbanization rate when $G_{u r}$ reaches its maximum) and $G_{u r}$ reaches its maximum $\left(G_{u r \max }\right)$. After $\left[(e-1) \times\left(1-P P_{u}\right)+1\right]^{2}-e \prec 0$, the process of urbanization would narrow the urban-rural disparity. Considering $\frac{\partial G_{u r}}{\partial e} \geq 0$, with the increase in $e$, $G_{u r}$ expands, and the value of $P P_{u \max }$ increases correspondingly. Moreover, $\frac{\partial^{2} G_{u r}}{\partial e^{2}} \prec 0$, that is, the effect of $e$ on urban-rural disparity decreases with an increase in $e$.

\footnotetext{
${ }^{2}$ In order to make a distinction in the urban population $P_{u}$ below, $P P_{u}$ here represents the urban population proportion.
} 
Overall, when $P P_{u}$ and $e$ vary together, the variation trends of the urban-rural Gini coefficient are shown in Fig. 1.

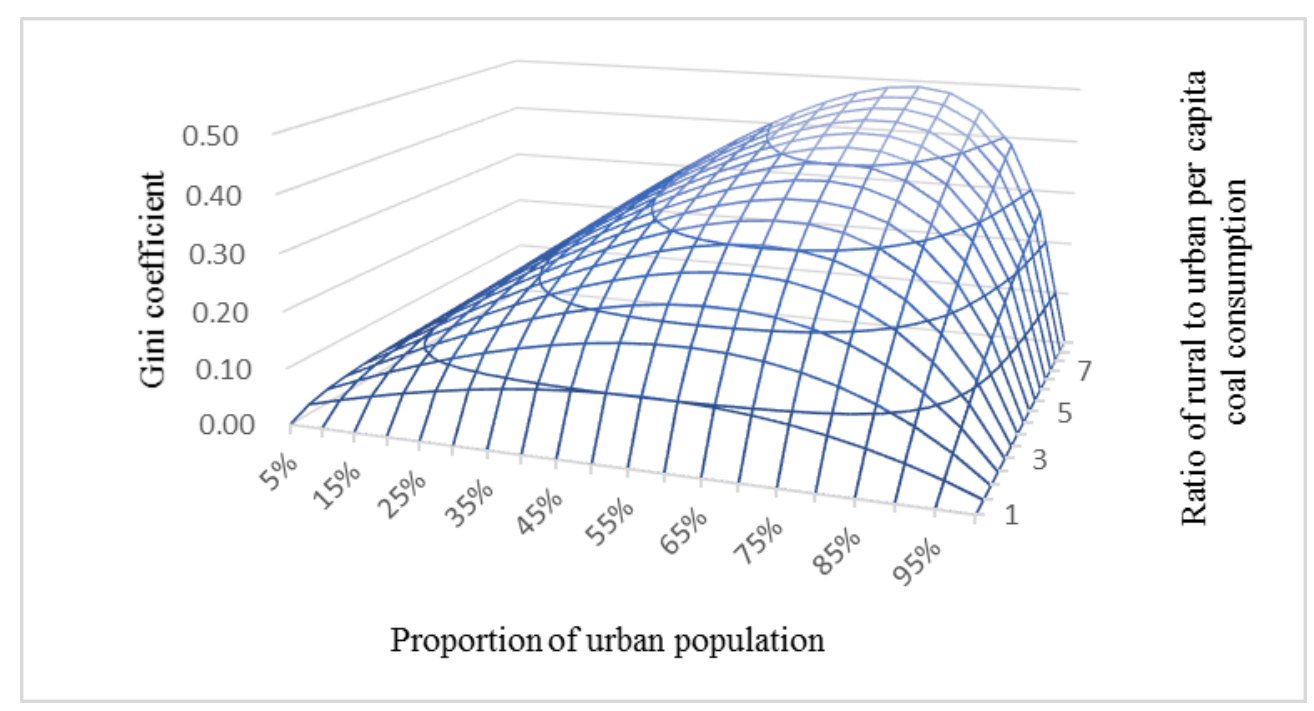

Fig. 1.

Variation trends of urban-rural residential coal consumption Gini coefficient.

Fig. 1 is a curve convex to the top right, showing that the urban-rural residential coal consumption Gini coefficient first expands and then narrows. Moreover, the urbanization rate corresponding to the maximum value of the urban-rural Gini coefficient continuously rises with an increase in the ratio of rural-to-urban per capita coal consumption.

To further measure the impact of $P P_{u}$ and $e$ on urban-rural disparity, the ratio of elasticity $R$ is calculated as follows:

$$
\begin{aligned}
& R=\frac{E\left(G_{u r}, e\right)}{E\left(G_{u r}, P P_{u}\right)} \\
& =\frac{e \times\left(1-P P_{u}\right)}{\left[(e-1) \times\left(1-P P_{u}\right)+1\right]^{2}-e}
\end{aligned}
$$

For further details, refer to the specified derivation in Appendix B.

$E\left(G_{u r}, e\right)$ and $E\left(G_{u r}, P P_{u}\right)$ represent the Gini coefficient elasticity to the ratio of rural-to-urban per capita coal consumption and urbanization rate, respectively. We can 
obtain $R$ simply by dividing $E\left(G_{u r}, e\right)$ by $E\left(G_{u r}, P P_{u}\right)$. As both elasticities measure a certain proportion of Gini coefficient's change occurring with respect to another variable, the ratio of the two elasticities shows the balance of power between ratio of rural-to-urban per capita coal consumption and urbanization rate.

In summary, previous literature does not introduce the ratio of rural-to-urban per capita coal consumption in the Gini coefficient and does not observe the variation of urban-rural disparity under the combined effects of per capita consumption proportion and urbanization rate.

Moreover, this study refers to the incremental decomposition of the Gini coefficient introduced by Chotikapanich and Griffiths (2001) to measure the contribution of $e$ and $P P_{u}$ to $\Delta G_{u r}$ :

$$
\Delta G_{u r}^{t}=M_{X}^{t}+M_{R}^{t}+M_{P}^{t}
$$

$M_{X}^{t}$ represents the contribution of consumption variation to the Gini coefficient increment, and can be expressed as the contribution of the variation in the ratio of rural-to-urban per capita coal consumption $\left(\Delta e^{t}\right) . M_{R}^{t}$ represents the contribution of consumption sequence variation to the Gini coefficient increment, which is 0 in this study, as urban per capita coal consumption has always been lower than rural per capita coal consumption. $M_{P}^{t}$ represents the contribution of urban population proportion $\left(\triangle P P_{u}^{t}\right)$ variation to the Gini coefficient increment.

\subsection{LMDI method for urban and rural residential coal consumption}

The LMDI method can be applied to quantify the contribution of relevant influencing factors to the variation of total quantity and to identify the underlying cause of the increase in urban-rural residential coal consumption disparity. As LMDI can be decomposed in many ways and since residential coal consumption increases with population and income growth and decreases with coal proportion and energy intensity decline, this study decomposes urban and rural residential coal consumption into coal proportion, energy intensity, income, and population effects. When 
considering the LMDI method for residential energy consumption, Zha et al. (2010), and Zhang and Guo (2013) considered similar decomposition effects.

To specify the derivation, the urban or rural aggregate residential coal consumption in year $t$ can be disaggregated into four parts as follows:

$$
\begin{aligned}
& E_{i}^{t}=\frac{E_{i}^{t}}{T E_{i}^{t}} \times \frac{T E_{i}^{t}}{I_{i}^{t}} \times \frac{I_{i}^{t}}{P_{i}^{t}} \times P_{i}^{t} \\
& =E S_{i}^{t} \times E I_{i}^{t} \times P I_{i}^{t} \times P_{i}^{t}
\end{aligned}
$$

where $i=u(r)$ represents the urban (rural) areas; $E_{i}^{t}$ represents urban (rural) residential coal consumption; $T E_{i}^{t}$ represents urban (rural) residential energy consumption; $I_{i}^{t}$ represents the urban (rural) per capita income; $P_{i}^{t}$ represents the urban (rural) population; $E S_{i}^{t}=\frac{E_{i}^{t}}{T E_{i}^{t}}$ represents urban (rural) coal proportion, which reflects the dependence of residents on coal consumption; $E I_{i}^{t}=\frac{T E_{i}^{t}}{I_{i}^{t}}$ represents urban (rural) energy consumption intensity, which reflects energy consumption under residential unit income; and $P I_{i}^{t}=\frac{I_{i}^{t}}{P_{i}^{t}}$ represents urban (rural) per capita income.

Following Ang and Liu (2007), the variation $\Delta E_{t o t(i=u / r)}^{t}$ of urban (rural) residential coal consumption from base period 0 to reporting period $t$ can be decomposed in the following form:

$$
\Delta E_{t o t(i=u / r)}^{t}=\Delta E S_{i}^{t}+\Delta E I_{i}^{t}+\Delta P I_{i}^{t}+\Delta P_{i}^{t}
$$

The formulas for computing the increments on the right side of the equations are as follows:

$$
\begin{gathered}
\Delta E S_{i}^{t}= \begin{cases}0, & \text { if } E_{i}^{t} \times E_{i}^{0}=0 \\
L\left(E_{i}^{t}, E_{i}^{0}\right) \ln \left(\frac{E S_{i}^{t}}{E S_{i}^{0}}\right), & \text { if } E_{i}^{t} \times E_{i}^{0} \neq 0\end{cases} \\
\Delta E I_{i}^{t}= \begin{cases}0, & \text { if } E_{i}^{t} \times E_{i}^{0}=0 \\
L\left(E_{i}^{t}, E_{i}^{0}\right) \ln \left(\frac{E I_{i}^{t}}{E I_{i}^{0}}\right), & \text { if } E_{i}^{t} \times E_{i}^{0} \neq 0\end{cases}
\end{gathered}
$$




$$
\begin{aligned}
& \Delta P I_{i}^{t}= \begin{cases}0, & \text { if } E_{i}^{t} \times E_{i}^{0}=0 \\
L\left(E_{i}^{t}, E_{i}^{0}\right) \ln \left(\frac{P I_{i}^{t}}{P I_{i}^{0}}\right), & \text { if } E_{i}^{t} \times E_{i}^{0} \neq 0\end{cases} \\
& \Delta P_{i}^{t}= \begin{cases}0, & \text { if } E_{i}^{t} \times E_{i}^{0}=0 \\
L\left(E_{i}^{t}, E_{i}^{0}\right) \ln \left(\frac{P_{i}^{t}}{P_{i}^{0}}\right), & \text { if } E_{i}^{t} \times E_{i}^{0} \neq 0\end{cases} \\
& \text { In formulas (7a)-(7d), } L(x, y)=\frac{(x-y)}{(\ln x-\ln y)} .
\end{aligned}
$$

\subsection{Decoupling index and elasticity analysis based on the LMDI method}

For inducing a decrease in the carbon intensity of industrial production, Diakoulaki and Mandaraka (2007) showed that effort was a general term that refers to all actions that directly or indirectly contribute to a decrease, including measures for reducing industrial energy intensity, shifting towards less energy-intensive industrial activities, and switching to cleaner energy forms. Since an increase in industrial output would promote carbon dioxide emissions, Diakoulaki and Mandaraka (2007) defined a decoupling index as a portion of output effect that was offset by positive emission reduction effects, in order to measure the extent to which these effects decouple industrial development from carbon dioxide emissions.

Based on this definition of decoupling index and considering that both income and population can increase residential energy consumption and indirectly increase coal consumption further, this study defines decoupling index as the portion of income and population effects that are offset by positive coal consumption reduction effects, including coal proportion and energy intensity effects. The decoupling index described in this study is different from the definition given by Zhang and Guo (2013), who classified the population effect as an effort to reduce residential energy consumption. For simplicity, the effects of income and population can be called the size effect, and the effects of coal proportion and energy intensity can be called the effort effect. It seems that the effort effect deserves more attention, as it is the key factor for finally deciding the amount of residential coal consumption, while the size effect is inevitable (e.g., population increase) and must sometimes be promoted (e.g., 
income increase). Tseng et al. (2016) pointed out that achieving sustainable resource consumption requires consumption efficiency improvement and consumption pattern change.

Specifically, the urban-rural residential coal consumption-decoupling index is $D_{u / r}^{t}$ as follows:

$$
\begin{aligned}
& \text { If }\left(\Delta P I_{u / r}^{t}+\Delta P_{u / r}^{t}\right) \geq 0, \\
& D_{u / r}^{t}=-\frac{\left(\Delta E S_{u / r}^{t}+\Delta E I_{u / r}^{t}\right)}{\left(\Delta P I_{u / r}^{t}+\Delta P_{u / r}^{t}\right)} \cdot(8) \\
& \text { If }\left(\Delta P I_{u / r}^{t}+\Delta P_{u / r}^{t}\right) \prec 0, \\
& D_{u / r}^{t}=\frac{\left(\Delta E S_{u / r}^{t}+\Delta E I_{u / r}^{t}\right)-\left(\Delta P I_{u / r}^{t}+\Delta P_{u / r}^{t}\right)}{\left(\Delta P I_{u / r}^{t}+\Delta P_{u / r}^{t}\right)} .
\end{aligned}
$$

(i) $D_{u / r}^{t} \geq 1$, denoting strong decoupling efforts, indicates that the relevant measures to reduce residential coal consumption could offset the pressure of an increase in domestic energy consumption led by income or population growth.

(ii) $1>D_{u / r}^{t} \geq 0$, denoting weak decoupling efforts, indicates that the relevant measures to reduce residential coal consumption could to some degree offset the pressure of an increase in domestic energy consumption led by income or population growth.

(iii) $D_{u / r}^{t} \leq 0$, denoting no decoupling efforts, indicates that the relevant measures to reduce residential coal consumption could not offset the pressure of an increase in domestic energy consumption led by income or population growth.

Besides the decoupling index, we can analyze the relationship between LMDI factors and the disparity in urban-rural residential coal consumption based on the LMDI method. In this regard, based on formulas (1) and (6), formula (10) below reflects the logical relationship between LMDI factors and the urban-rural residential coal consumption Gini coefficient.

$$
G_{u r}=\frac{P_{u}}{P_{u}+P_{r}}-\frac{E S_{u} \times E I_{u} \times P I_{u} \times P_{u}}{E S_{u} \times E I_{u} \times P I_{u} \times P_{u}+E S_{r} \times E I_{r} \times P I_{r} \times P_{r}}
$$


Furthermore, with reference to elasticity analysis, based on the LMDI effects of Lu et al. (2015), formulas (11)-(12) construct the elasticity index of the Gini coefficient and LMDI effects, which possibly shows the reaction of the rate of variation in urban-rural residential coal consumption disparity to the rate of variation in coal proportion, energy intensity, per capita income, and population.

$$
\begin{gathered}
\varepsilon_{u M}=\frac{\frac{\Delta G_{u r}}{G_{u r}^{t}}}{\frac{\Delta M_{u}}{E_{u}^{t}}} \\
\varepsilon_{r M}=\frac{\frac{\Delta G_{u r}}{G_{u r}^{t}}}{\frac{\Delta M_{r}}{E_{r}^{t}}}
\end{gathered}
$$

$\Delta M_{u}$ and $\Delta M_{r}$ represent $\Delta E S_{u}, \Delta E I_{u}, \Delta P I_{u}, \Delta P_{u}$ and $\Delta E S_{r}, \Delta E I_{r}, \Delta P I_{r}, \Delta P_{r}$, respectively.

\subsection{Data}

The research period of this study covers 2000 to 2015 . The purpose of the study is to analyze the disparity in China's urban-rural residential coal consumption in recent years. As the China Energy Statistical Yearbook (2001-2016) lists urban and rural residential energy (including coal) consumption separately, it is convenient to use these data directly for our research. Some studies in the literature (e.g., Fan et al., 2013; Wang and Yang, 2014) have used these sources to collect data for their research. The related energy data, income, income index, and population are listed in Table 1.

\section{Table 1}

\begin{tabular}{|c|c|c|c|c|c|}
\hline Year & $\begin{array}{l}\text { Coal Total } \\
\text { (coal equivalent }\end{array}$ & $\begin{array}{l}\text { Energy Total } \\
\text { (coal equivalent }\end{array}$ & $\begin{array}{l}\text { Per capita annual } \\
\text { income (current }\end{array}$ & $\begin{array}{l}\text { Income Index } \\
(2000=100)\end{array}$ & $\begin{array}{c}\text { Population } \\
\text { (10,000 people) }\end{array}$ \\
\hline & calculation, 10,000 & calculation, 10,000 & prices, RMB yuan) & & \\
\hline & tce) & tce) & & & \\
\hline
\end{tabular}

Related energy data, income, index, and population. 


\begin{tabular}{ccccccccccc}
\hline & Urban & Rural & Urban & Rural & Urban & Rural & Urban & Rural & Urban & Rural \\
\hline 2000 & 2067.77 & 4077.68 & 9529.68 & 7165.36 & 6280.0 & 2253.4 & 100.0 & 100.0 & 45906 & 80837 \\
2001 & 2033.87 & 3960.16 & 9859.52 & 7441.50 & 6859.6 & 2366.4 & 108.5 & 104.2 & 48064 & 79563 \\
2002 & 2040.99 & 4298.30 & 10552.28 & 8089.77 & 7702.8 & 2475.6 & 123.0 & 109.2 & 50212 & 78241 \\
2003 & 2246.36 & 4865.08 & 12214.72 & 9233.27 & 8472.2 & 2622.2 & 134.1 & 113.9 & 52376 & 76851 \\
2004 & 2385.67 & 5468.92 & 14069.64 & 10674.89 & 9421.6 & 2936.4 & 144.4 & 121.6 & 54283 & 75705 \\
2005 & 2333.74 & 5709.96 & 15891.42 & 11681.48 & 10493.0 & 3254.9 & 158.3 & 129.2 & 56212 & 74544 \\
2006 & 2320.42 & 5510.93 & 17633.46 & 12469.02 & 11759.5 & 3587.0 & 174.8 & 138.7 & 58288 & 73160 \\
2007 & 2137.87 & 5208.42 & 19452.32 & 13438.79 & 13785.8 & 4140.4 & 196.1 & 151.9 & 60633 & 71496 \\
2008 & 1803.33 & 5082.37 & 19905.93 & 13783.22 & 15780.8 & 4760.6 & 212.6 & 164.1 & 62403 & 70399 \\
2009 & 1501.45 & 4967.01 & 20832.28 & 14340.29 & 17174.7 & 5153.2 & 233.4 & 178.0 & 64512 & 68938 \\
2010 & 1372.50 & 5618.70 & 21055.38 & 15414.25 & 19109.4 & 5919.0 & 251.6 & 197.4 & 66978 & 67113 \\
2011 & 1334.67 & 6061.48 & 22522.34 & 17061.32 & 21809.8 & 6977.3 & 272.7 & 219.9 & 69079 & 65656 \\
2012 & 1185.21 & 6307.84 & 24113.34 & 18192.50 & 24564.7 & 7916.6 & 298.9 & 243.5 & 71182 & 64222 \\
2013 & 1028.83 & 6048.09 & 25725.57 & 19805.27 & 26955.1 & 8859.9 & 319.8 & 266.1 & 73111 & 62961 \\
2014 & 1022.88 & 5858.33 & 26946.49 & 20265.84 & 29381.0 & 9892.0 & 341.5 & 290.6 & 74916 & 61866 \\
2015 & 985.17 & 5984.27 & 28668.14 & 21430.83 & 31790.3 & 10772.0 & 364.1 & 312.4 & 77116 & 60346 \\
\hline
\end{tabular}

Notes: Data in Table 1 are collected from the China Statistical Yearbook (2016) and

China Energy Statistical Yearbook (2001-2016). Data in Tables 2-7 and Figs. 1-6 are calculated by the authors based on Table 1 .

\section{Results}

\subsection{Analysis of urban-rural residential coal consumption Gini coefficient}

As shown in Fig. 2, China's urban and rural per capita residential coal consumption have grown in opposite directions in recent years, with urban residents consuming less coal and rural residents using more ${ }^{3}$. At the same time, the

\footnotetext{
${ }^{3}$ As shown in Fig. 2, there is a turning point in the rural per capita residential coal consumption in 2009, caused by the maximum increase of total rural residential coal consumption in the same year. Moreover, as shown in Table 5, the LMDI results for rural areas demonstrate that the maximum increase of rural residential coal consumption in 2009 was mainly caused by the positive coal proportion effect. In other words, rural residential coal proportion has been decreasing year by year, except in 2009. Hence, rural residential coal consumption increased in 2009, which then led to a turning point in 2009.
} 
urban-rural residential coal consumption Gini coefficient has increased, rising from less than 0.1 in 2000 to 0.208 in 2009 and to 0.42 in 2015 (see Table 2). Clearly, the current urban-rural disparity should not be ignored. Lower coal usage by urban residents deserves to be encouraged and promoted, but the continued increase in coal consumption of rural residents has to be addressed by the concerned government departments and institutions. Moreover, in order to achieve Target 7 in the new United Nations Sustainable Development Goals to "ensure access to affordable, reliable, sustainable, and modern energy for all" by 2030, the residential coal consumption disparity between urban and rural areas must be investigated.

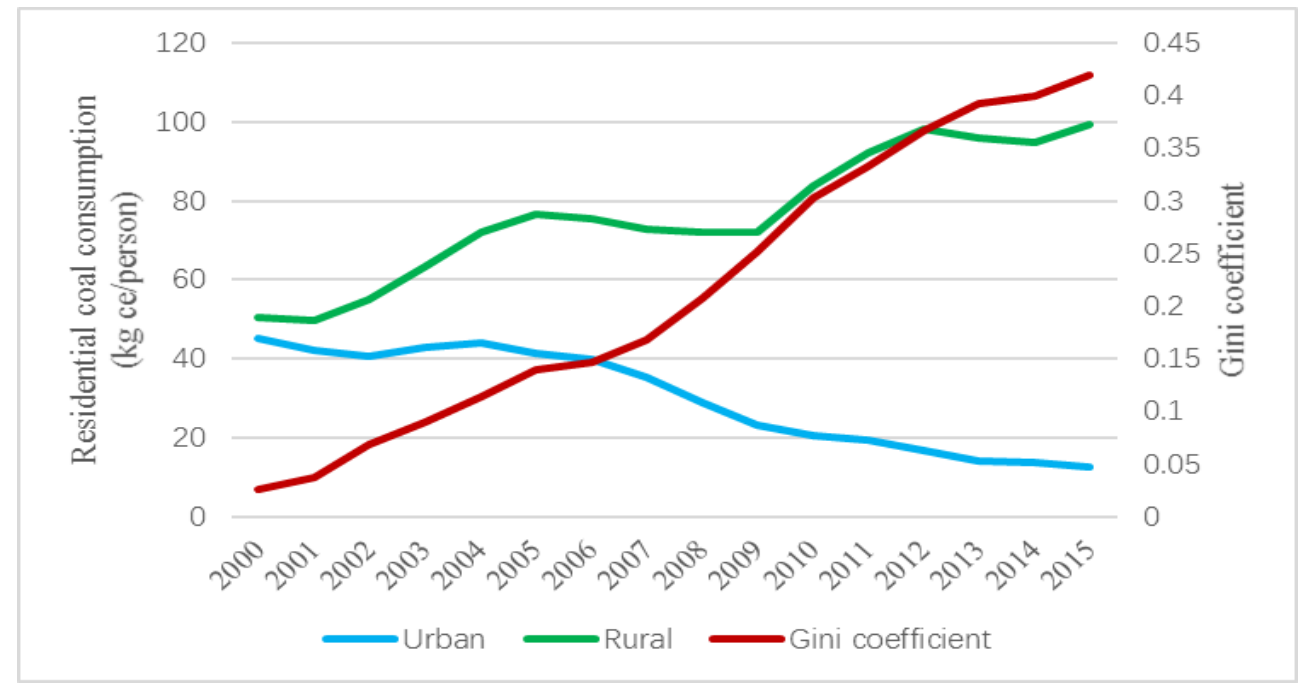

Fig. 2.

Urban and rural per capita residential coal consumption and Gini coefficient.

\section{Table 2}

Urban-rural residential coal consumption, Gini coefficient, and influencing factors.

\begin{tabular}{|c|c|c|c|c|c|c|c|c|}
\hline Year & $\begin{array}{c}\text { Rural coal } \\
\text { consumption } \\
\text { (kg ce/person) }\end{array}$ & $\begin{array}{l}\text { Urban coal } \\
\text { consumption } \\
\text { (kg ce/person) }\end{array}$ & $e$ & $P P_{u}$ & $G_{u r}$ & $\frac{\partial G_{u r}}{\partial e}$ & $\frac{\partial G_{u r}}{\partial P P_{u}}$ & $R$ \\
\hline 2000 & 50.44 & 45.04 & 1.12 & 0.36 & 0.03 & 0.20 & 0.03 & 18.37 \\
\hline 2001 & 49.77 & 42.32 & 1.18 & 0.38 & 0.04 & 0.19 & 0.05 & 13.20 \\
\hline 2002 & 54.94 & 40.65 & 1.35 & 0.39 & 0.07 & 0.16 & 0.08 & 6.72 \\
\hline
\end{tabular}




\begin{tabular}{lllllllll}
2003 & 63.31 & 42.89 & 1.48 & 0.41 & 0.09 & 0.15 & 0.10 & 5.15 \\
2004 & 72.24 & 43.95 & 1.64 & 0.42 & 0.11 & 0.13 & 0.13 & 3.88 \\
2005 & 76.60 & 41.52 & 1.85 & 0.43 & 0.14 & 0.11 & 0.16 & 3.00 \\
2006 & 75.33 & 39.81 & 1.89 & 0.44 & 0.15 & 0.11 & 0.16 & 3.03 \\
2007 & 72.85 & 35.26 & 2.07 & 0.46 & 0.17 & 0.10 & 0.17 & 2.66 \\
2008 & 72.19 & 28.90 & 2.50 & 0.47 & 0.21 & 0.08 & 0.22 & 1.84 \\
2009 & 72.05 & 23.27 & 3.10 & 0.48 & 0.25 & 0.06 & 0.29 & 1.29 \\
2010 & 83.72 & 20.49 & 4.09 & 0.50 & 0.30 & 0.04 & 0.37 & 0.86 \\
2011 & 92.32 & 19.32 & 4.78 & 0.51 & 0.33 & 0.03 & 0.41 & 0.71 \\
2012 & 98.22 & 16.65 & 5.90 & 0.53 & 0.37 & 0.02 & 0.47 & 0.54 \\
2013 & 96.06 & 14.07 & 6.83 & 0.54 & 0.39 & 0.02 & 0.50 & 0.46 \\
2014 & 94.69 & 13.65 & 6.94 & 0.55 & 0.40 & 0.02 & 0.49 & 0.47 \\
2015 & 99.17 & 12.78 & 7.76 & 0.56 & 0.42 & 0.02 & 0.51 & 0.43 \\
\hline
\end{tabular}

According to Table 2, with regard to the influencing factors of the urban-rural residential coal consumption Gini coefficient, the ratio of rural-to-urban per capita coal consumption ( $e$ ) was 1.12 in 2000 and grew to 7.76 in 2015, while the urbanization rate $\left(P P_{u}\right)$ increased from 0.36 in 2000 to 0.56 in 2015. Moreover, based on formulas (2)-(4), Table 2 lists the impacts of $e_{\text {and }} P P_{u}$ and their elasticity ratio $R$. Both $\frac{\partial G_{u r}}{\partial e}$ and $\frac{\partial G_{u r}}{\partial P P_{u}}$ were positive in 2000-2015, implying that both the ratio of rural-to-urban per capita coal consumption and the urbanization rate triggered the increase in the Gini coefficient. However, $\frac{\partial G_{u r}}{\partial e}$ decreased from 0.20 in 2000 to 0.02 in 2015, while $\frac{\partial G_{u r}}{\partial P P_{u}}$ increased from 0.03 to 0.51 during this period, indicating that the effect of the former declined while that of the latter was even more prominent. The ratio of elasticity between $\frac{\partial G_{u r}}{\partial e}$ and $\frac{\partial G_{u r}}{\partial P P_{u}}$ directly shows their contrasting strength. In 2000, the contrast between the two forces was 18.38 , and the force of 
$\frac{\partial G_{u r}}{\partial e}$ was far more than that of $\frac{\partial G_{u r}}{\partial P P_{u}}$. However, in 2009, the contrast reached 1.29, and the two forces essentially remained flat. In 2015, the contrast reached 0.43 , and $\frac{\partial G_{u r}}{\partial P P_{u}}$ moved higher than $\frac{\partial G_{u r}}{\partial e}$.

In addition, as $\frac{\partial G_{u r}}{\partial P P_{u}}$ was positive in 2000-2015, $G_{u r}$ increased following rapid urbanization during this period. As shown in Fig. 1, the urban-rural residential coal consumption Gini coefficient during 2000-2015 was on the left side of the surface in Fig. 1, and did not reach $G_{u r \max }$. Meanwhile, with the increase in the ratio of rural-to-urban per capita coal consumption, the Gini coefficient moved towards the right side of the surface in Fig. 1, and the urban-rural residential coal consumption disparity will likely grow within a short time as the real $P P_{u}$ was still lower than the $P P_{u \max }$. However, as the existing literature has not revealed the reasons for the increase in the urban-rural residential coal consumption disparity and its variation trends, this analysis and conclusions could help fill this gap.

Furthermore, based on formula (5), Table 3 lists the contributions of the ratio of rural-to-urban per capita coal consumption and the urbanization rate. From the contribution rate, it is found that $\frac{\Delta e^{t}}{\Delta G_{u r}^{t}}$ is much larger than $\frac{\Delta P P_{u}^{t}}{\Delta G_{u r}^{t}}$ in most years. However, the former declined and the latter increased. Broadly, although the impact of the ratio of rural-to-urban per capita coal consumption has declined, it is the key reason for the widening of the urban-rural residential coal consumption disparity in most years.

\section{Table 3}

Incremental decomposition of urban-rural residential coal consumption Gini coefficient. 


\begin{tabular}{|c|c|c|c|c|c|}
\hline Year & $\Delta G_{u r}^{t}$ & $\Delta e^{t}$ & $\Delta P P_{u}^{t}$ & $\frac{\Delta e^{t}}{\Delta G_{u r}^{t}}$ & $\frac{\Delta P P_{u}^{t}}{\Delta G_{u r}^{t}}$ \\
\hline 2000-2001 & 0.0116 & 0.0109 & 0.0007 & $93.97 \%$ & $6.03 \%$ \\
\hline 2001-2002 & 0.0317 & 0.0304 & 0.0013 & $95.90 \%$ & $4.10 \%$ \\
\hline 2002-2003 & 0.0205 & 0.0189 & 0.0016 & $92.20 \%$ & $7.80 \%$ \\
\hline 2003-2004 & 0.0244 & 0.0228 & 0.0016 & $93.44 \%$ & $6.56 \%$ \\
\hline 2004-2005 & 0.0259 & 0.0239 & 0.0020 & $92.28 \%$ & $7.72 \%$ \\
\hline 2005-2006 & 0.0074 & 0.0052 & 0.0022 & $70.27 \%$ & $29.73 \%$ \\
\hline 2006-2007 & 0.0207 & 0.018 & 0.0027 & $86.96 \%$ & $13.04 \%$ \\
\hline 2007-2008 & 0.0401 & 0.0376 & 0.0025 & $93.77 \%$ & $6.23 \%$ \\
\hline 2008-2009 & 0.0433 & 0.0393 & 0.0040 & $90.76 \%$ & $9.24 \%$ \\
\hline 2009-2010 & 0.0519 & 0.0458 & 0.0061 & $88.25 \%$ & $11.75 \%$ \\
\hline 2010-2011 & 0.0291 & 0.0235 & 0.0056 & $80.76 \%$ & $19.24 \%$ \\
\hline 2011-2012 & 0.0353 & 0.0291 & 0.0062 & $82.44 \%$ & $17.56 \%$ \\
\hline 2012-2013 & 0.0244 & 0.0185 & 0.0059 & $75.82 \%$ & $24.18 \%$ \\
\hline 2013-2014 & 0.0071 & 0.0020 & 0.0052 & $28.17 \%$ & $73.24 \%$ \\
\hline 2014-2015 & 0.0206 & 0.0137 & 0.0069 & $66.50 \%$ & $33.50 \%$ \\
\hline 2000-2015 & 0.3939 & 0.2683 & 0.1256 & $68.11 \%$ & $31.89 \%$ \\
\hline
\end{tabular}

In summary, even though some studies showed a large urban-rural disparity in China's residential energy consumption (e.g., Niu et al., 2012; Zheng et al., 2014), there is little research devoted exclusively to the growing urban-rural disparity in residential coal consumption. Based on the expanded calculation approach of the urban-rural Gini coefficient, which merges $E_{u}$ and $E_{r}$ into a simple $e$, the abovementioned analysis not only measures the urban-rural disparity in residential coal consumption but also presents its variation trend and incremental decomposition. The following analysis in Subsections 3.2 and 3.3 uses the LMDI method and combines it with the Gini coefficient to discuss the underlying factors influencing the disparity in urban-rural residential coal consumption. 


\subsection{LMDI decomposition analysis for urban-rural residential coal consumption}

Section 2 shows that urban and rural residential coal consumption can be decomposed into coal proportion, energy intensity, income, and population effects. Figs. 3-6 show the variation trends of the four effects by urban and rural characteristics.



Fig. 3.

Urban and rural residential coal proportion.

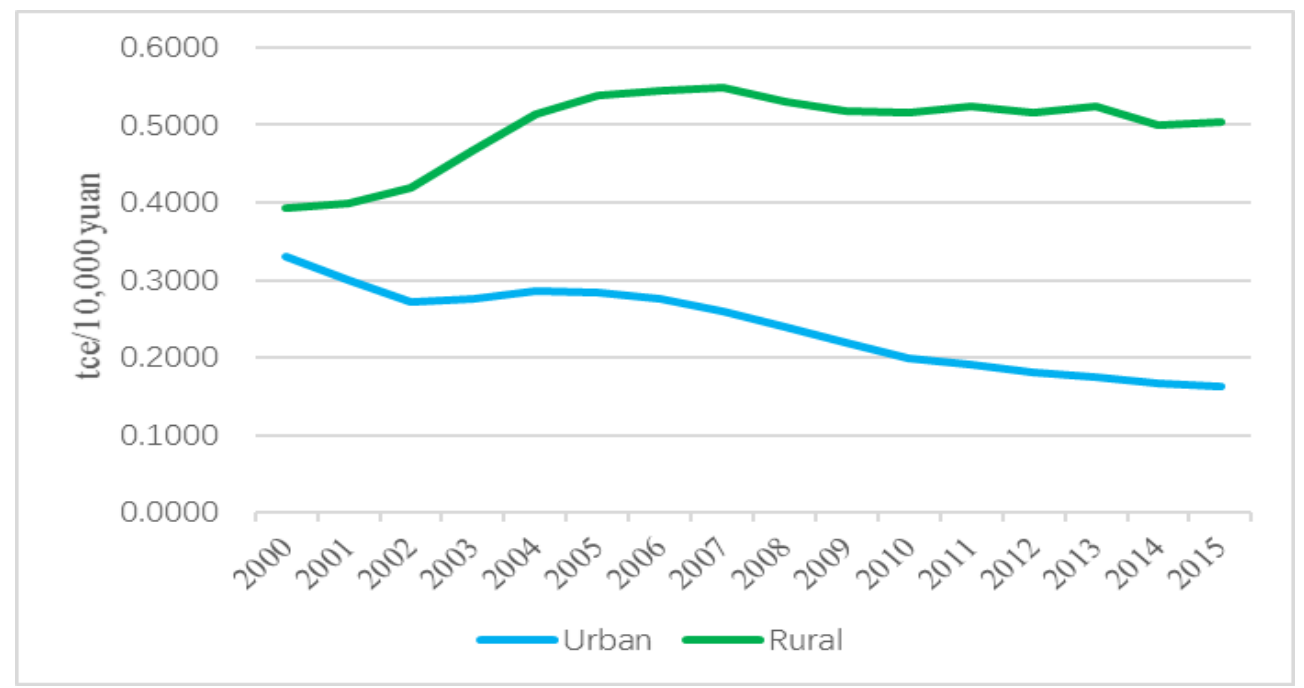

Fig. 4.

Urban and rural residential energy intensity. 


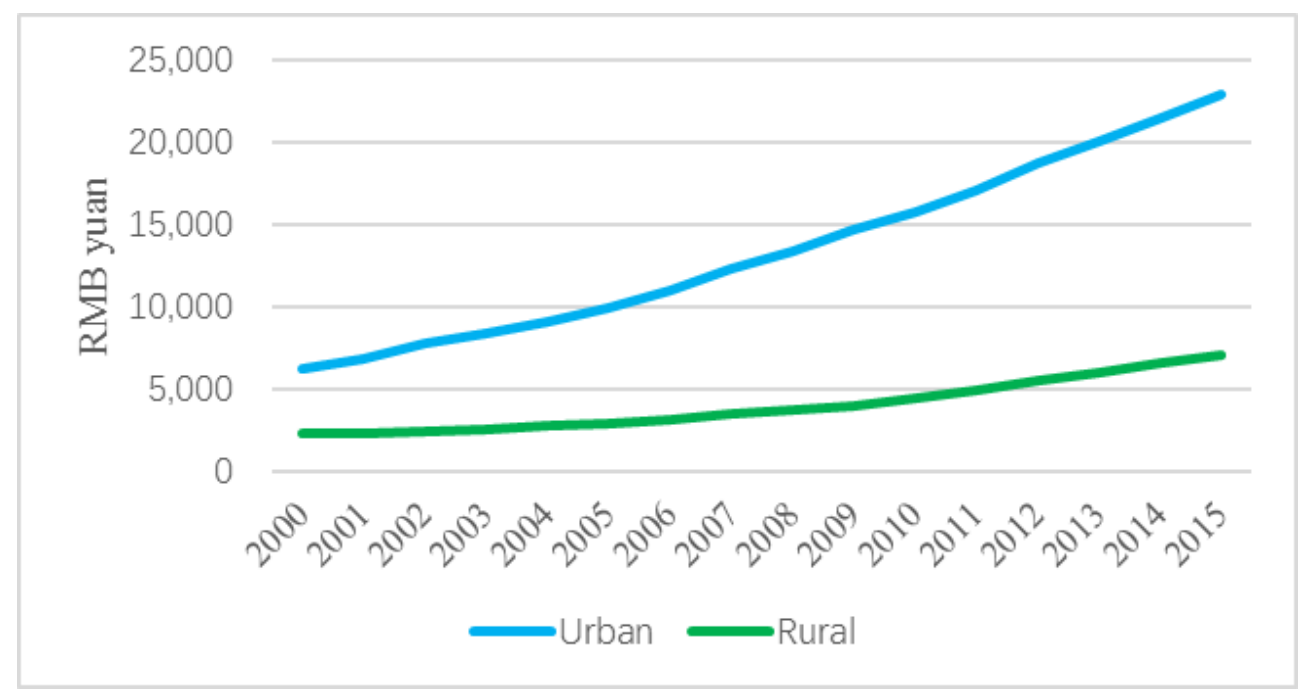

\section{Fig. 5.}

Urban and rural per capita residential income.



Fig. 6.

Urban and rural population.

According to Figs. 3-6, (i) urban and rural coal proportion during 2000-2015 showed a declining trend, with the former always lower than the latter; (ii) urban and rural energy intensity moved in the opposite directions during 2000-2015, as the former decreased and the latter increased; (iii) both urban and rural per capita income grew, although the former grew at a higher rate than the latter did; and (iv) urban 
population increased while rural population declined alongside urbanization, with the former surpassing the latter for the first time in 2011. Generally speaking, Figs. 2, 3, and 5 showed the opposite effect, whereby rural regions have higher coal proportion and consumption, but lower personal income. However, urban regions have lower coal proportion and consumption, but higher personal income, which confirms the energy ladder assumption to some extent.

According to The Sustainable Development Goals Report (2017), $96 \%$ of urban residents worldwide could access electricity in 2014 , while the share was only $73 \%$ in rural areas worldwide. The higher proportion of coal consumption in rural areas is shown in Fig. 3, indicating a lower proportion of modern energy consumption, such as electricity use, in China's rural regions during 2002 to 2015. Thus, China is no exception to the global urban-rural sustainable energy consumption gap.

The findings obtained from the decomposition analysis in formulas (7a)-(7d) are presented in Tables 4-5. Generally, the decline in urban coal proportion and rural per capita income growth were the dominant reasons for the decreasing levels of urban residential coal consumption and the increasing trends in rural residential coal consumption. Furthermore, both the urban coal proportion effect and the rural income effect were indirect factors leading to an increase in urban-rural residential coal consumption Gini coefficient in recent years.

\section{Table 4}

Complete decomposition of urban residential coal consumption change (unit: 10,000 tce).

\begin{tabular}{cccccc}
\hline Year & $\Delta E S_{u}^{t}$ & $\Delta E I_{u}^{t}$ & $\Delta P I_{u}^{t}$ & $\Delta P_{u}^{t}$ & $\Delta E_{u}^{\text {tot }}$ \\
\hline $2000-2001$ & -103.68 & -191.66 & 167.23 & 94.21 & -33.90 \\
$2001-2002$ & -131.23 & -207.00 & 256.28 & 89.08 & 7.12 \\
$2002-2003$ & -108.01 & 38.36 & 184.64 & 90.38 & 205.37 \\
$2003-2004$ & -188.02 & 72.88 & 171.65 & 82.80 & 139.31 \\
$2004-2005$ & -339.24 & -11.38 & 216.29 & 82.40 & -51.93 \\
$2005-2006$ & -255.38 & -73.03 & 230.69 & 84.39 & -13.32 \\
\hline
\end{tabular}




\begin{tabular}{llllll}
\hline $2006-2007$ & -401.26 & -125.55 & 256.38 & 87.88 & -182.55 \\
$2007-2008$ & -379.86 & -169.79 & 158.54 & 56.57 & -334.54 \\
$2008-2009$ & -376.83 & -133.43 & 153.61 & 54.77 & -301.88 \\
$2009-2010$ & -144.25 & -146.37 & 107.79 & 53.87 & -128.95 \\
$2010-2011$ & -128.99 & -59.84 & 109.20 & 41.80 & -37.83 \\
$2011-2012$ & -235.36 & -67.15 & 115.31 & 37.74 & -149.46 \\
$2012-2013$ & -227.91 & -32.83 & 74.80 & 29.55 & -156.38 \\
$2013-2014$ & -53.52 & -44.99 & 67.54 & 25.02 & -5.95 \\
$2014-2015$ & -99.89 & -30.98 & 64.10 & 29.06 & -37.71 \\
\hline $2000-2015$ & -2690.81 & -1035.99 & 1886.78 & 757.42 & -1082.60 \\
\hline
\end{tabular}

\section{Table 5}

Complete decomposition of rural residential coal consumption change (unit: 10,000 tce).

\begin{tabular}{cccccc}
\hline Year & $\Delta E S_{r}^{t}$ & $\Delta E I_{r}^{t}$ & $\Delta P I_{r}^{t}$ & $\Delta P_{r}^{t}$ & $\Delta E_{r}^{\text {tot }}$ \\
\hline $2000-2001$ & -269.48 & 50.49 & 165.31 & -63.84 & -117.52 \\
$2001-2002$ & -6.57 & 220.20 & 193.66 & -69.15 & 338.14 \\
$2002-2003$ & -38.21 & 494.36 & 192.65 & -82.02 & 566.78 \\
$2003-2004$ & -144.94 & 487.14 & 339.18 & -77.54 & 603.84 \\
$2004-2005$ & -262.55 & 253.39 & 336.57 & -86.37 & 241.04 \\
$2005-2006$ & -565.03 & 70.75 & 400.38 & -105.13 & -199.03 \\
$2006-2007$ & -703.83 & 38.44 & 486.16 & -123.28 & -302.51 \\
$2007-2008$ & -256.26 & -186.52 & 396.29 & -79.56 & -126.05 \\
$2008-2009$ & -314.44 & -105.32 & 409.77 & -105.37 & -115.36 \\
$2009-2010$ & 269.93 & -23.28 & 546.87 & -141.83 & 651.69 \\
$2010-2011$ & -149.83 & 90.56 & 630.17 & -128.12 & 442.78 \\
$2011-2012$ & -150.61 & -94.75 & 628.28 & -136.56 & 246.36 \\
$2012-2013$ & -784.42 & 97.63 & 549.53 & -122.49 & -259.75 \\
$2013-2014$ & -326.60 & -282.41 & 523.70 & -104.44 & -189.76 \\
$2014-2015$ & -205.01 & 49.84 & 428.40 & -147.29 & 125.94 \\
\hline & & & & & \\
\hline
\end{tabular}




\begin{tabular}{llllll}
\hline $2000-2015$ & -3538.60 & 1236.71 & 5661.46 & -1452.98 & 1906.59 \\
\hline
\end{tabular}

During 2000-2015, the coal proportion effect declined 26.91 million tce and 35.39 million tce for urban and rural residential coal consumption, respectively, following a decrease in both urban and rural coal proportion, as shown in Fig. 3. In addition, due to a greater decreasing margin, the rural coal proportion effect was larger than the urban coal proportion effect, as shown in Fig. 3. The income effect added 18.87 million tce and 56.61 million tce to urban and rural residential coal consumption during 2000-2015, respectively. Clearly, the rural income effect was far greater than the urban income effect. Overall, coal proportion and income effects determined the disparity in urban and rural residential coal consumption. However, the coal proportion effect was the leading factor, completely offsetting the income effect, and remained at 8.04 million tce for urban coal consumption, while the income effect was the dominant factor, counterbalancing the coal proportion effect completely and remaining at 21.23 million tce for rural coal consumption. Incidentally, Yao et al. (2012) provided a similar empirical result: the increase of rural residential commercial energy consumption mainly originated from rural income growth. Moreover, the income effect playing a leading role in the increase of rural residential consumption, which offers a modest explanation for the energy ladder theory, as coal is part of commercial energy. Simultaneously, as coal is not at the top of the energy ladder of residential energy use, the coal proportion effect takes an absolute strength in urban regions, and causes the reduction of urban residential coal consumption with the growth of urban personal income.

Furthermore, the energy intensity effect and population effect cannot be overlooked, and both effects have generally offset each other. For example, during 2000-2015, urban residential coal consumption reduced by 10.36 million tce due to a reduction in energy intensity, but increased by 7.57 million tce because of an increase in urban population. At the same time, driven by rising energy intensity, rural 
residential coal consumption increased by 12.37 million tce in total and declined by 14.53 million tce owing to rural depopulation.

\subsection{Decoupling index based on LMDI method and elasticity analysis for Gini coefficient}

Based on the results of LMDI decomposition in Subsection 3.2 and formulas (8)-(9), the effort effect $\left(\Delta E S_{u / r}^{t}+\Delta E I_{u / r}^{t}\right)$, size effect $\left(\Delta P I_{u / r}^{t}+\Delta P_{u / r}^{t}\right)$, and responding decoupling index $\left(D_{u / r}^{t}\right)$ in urban and rural areas from 2000 to 2015 are listed in Table 6.

\section{Table 6}

Decoupling index between effort effect and size effect in urban and rural areas.

\begin{tabular}{ccccccccc}
\hline & \multicolumn{2}{c}{$\Delta E S_{u / r}^{t}+\Delta E I_{u / r}^{t}$} & \multicolumn{2}{c}{$\Delta P I_{u / r}^{t}+\Delta P_{u / r}^{t}$} & \multicolumn{3}{c}{$D_{u / r}^{t}$} \\
Year & $(10,000$ tce $)$ & $(10,000$ tce $)$ & & & \\
\cline { 2 - 9 } & Urban & Rural & Urban & Rural & Urban & Rural \\
\hline $2000-2001$ & -295.34 & -218.99 & 261.44 & 101.47 & 1.13 & Strong & 2.16 & Strong \\
$2001-2002$ & -338.23 & 213.63 & 345.35 & 124.51 & 0.98 & Weak & -1.72 & No \\
$2002-2003$ & -69.65 & 456.15 & 275.02 & 110.63 & 0.25 & Weak & -4.12 & No \\
$2003-2004$ & -115.14 & 342.20 & 254.45 & 261.64 & 0.45 & Weak & -1.31 & No \\
$2004-2005$ & -350.61 & -9.16 & 298.68 & 250.20 & 1.17 & Strong & 0.04 & Weak \\
$2005-2006$ & -328.41 & -494.28 & 315.09 & 295.25 & 1.04 & Strong & 1.67 & Strong \\
$2006-2007$ & -526.81 & -665.40 & 344.26 & 362.89 & 1.53 & Strong & 1.83 & Strong \\
$2007-2008$ & -549.64 & -442.78 & 215.10 & 316.73 & 2.56 & Strong & 1.40 & Strong \\
$2008-2009$ & -510.26 & -419.76 & 208.38 & 304.40 & 2.45 & Strong & 1.38 & Strong \\
$2009-2010$ & -290.61 & 246.65 & 161.66 & 405.04 & 1.80 & Strong & -0.61 & No \\
$2010-2011$ & -188.84 & -59.27 & 151.01 & 502.05 & 1.25 & Strong & 0.12 & Weak \\
$2011-2012$ & -302.51 & -245.36 & 153.05 & 491.72 & 1.98 & Strong & 0.50 & Weak \\
$2012-2013$ & -260.73 & -686.79 & 104.35 & 427.04 & 2.50 & Strong & 1.61 & Strong \\
$2013-2014$ & -98.51 & -609.02 & 92.56 & 419.26 & 1.06 & Strong & 1.45 & Strong \\
\hline
\end{tabular}




\begin{tabular}{rrrrrrrrr}
\hline $2014-2015$ & -130.86 & -155.17 & 93.15 & 281.11 & 1.40 & Strong & 0.55 & Weak \\
\hline $2000-2015$ & -3726.80 & -2301.89 & 2644.20 & 4208.48 & 1.41 & Strong & 0.55 & Weak \\
\hline
\end{tabular}

Note: "Strong" denotes "strong decoupling"; "Weak" denotes "weak decoupling"; and "No" denotes "no decoupling."

During 2000 to 2015, size effects were positive and effort effects were negative for urban areas. Therefore, the growth in urban population and income per capita promote urban household coal consumption, while the deduction in urban coal consumption proportion and energy consumption intensity decrease urban household coal consumption. Moreover, most decoupling indexes in urban areas from 2000 to 2015 denote strong decoupling, indicating that effort effects have overcome size effects. In other words, such measures as replacing coal with electricity and using more efficient energy forms in household energy consumption have reduced urban household coal consumption effectively, although the growth of urban population and income per capita generate ever-increasing demand for energy in urban areas.

Unlike urban areas, decoupling indexes were not stable in rural areas, denoting strong decoupling, weak decoupling, and no decoupling effects from 2000 to 2015. In addition, size effects were positive in rural areas, as in urban areas, while effort effects were positive in most years. From the accumulative perspective and using 2000 as the baseline, the decoupling index in rural areas reached weak decoupling only in 2015. Thus, we conclude that the pressure of increased coal consumption by rural residents was not lower than that of urban residents, despite rural depopulation. Moreover, measures to reduce rural residential coal consumption were effective only to some degree, and thus, need to be strengthened in the future.

Moreover, LMDI decomposition effects, such as coal proportion, energy intensity, income, and population effects, can be used to determine the urban-rural residential coal consumption Gini coefficient, according to formula (10). Based on formulas (11)-(12), the elasticities of the urban-rural Gini coefficient to each LMDI effect are presented in Table 7. 
Table 7

Elasticities of urban-rural Gini coefficient to LMDI effects.

\begin{tabular}{|c|c|c|c|c|c|c|c|c|}
\hline \multirow[b]{2}{*}{ Year } & \multicolumn{4}{|c|}{ Urban } & \multicolumn{4}{|c|}{ Rural } \\
\hline & $\varepsilon_{E S_{u}}$ & $\varepsilon_{E I_{u}}$ & $\varepsilon_{P I_{u}}$ & $\varepsilon_{P_{u}}$ & $\varepsilon_{E S_{r}}$ & $\varepsilon_{E I_{r}}$ & $\varepsilon_{P I_{r}}$ & $\varepsilon_{P_{r}}$ \\
\hline 2000-2001 & -6.08 & -3.29 & 3.77 & 6.69 & -4.55 & 24.31 & 7.43 & -19.23 \\
\hline 2001-2002 & -7.14 & -4.53 & 3.66 & 10.52 & -300.30 & 8.96 & 10.19 & -28.54 \\
\hline 2002-2003 & -4.76 & 13.42 & 2.79 & 5.69 & -29.17 & 2.25 & 5.78 & -13.59 \\
\hline 2003-2004 & -2.72 & 7.03 & 2.98 & 6.19 & -8.10 & 2.41 & 3.46 & -15.14 \\
\hline 2004-2005 & -1.27 & -38.01 & 2.00 & 5.25 & -4.03 & 4.18 & 3.14 & -12.25 \\
\hline 2005-2006 & -0.45 & -1.59 & 0.50 & 1.38 & -0.49 & 3.90 & 0.69 & -2.62 \\
\hline 2006-2007 & -0.66 & -2.10 & 1.03 & 3.01 & -0.91 & 16.75 & 1.32 & -5.22 \\
\hline 2007-2008 & -0.92 & -2.05 & 2.19 & 6.15 & -3.83 & -5.26 & 2.47 & -12.32 \\
\hline 2008-2009 & -0.69 & -1.94 & 1.68 & 4.72 & -2.72 & -8.13 & 2.09 & -8.12 \\
\hline 2009-2010 & -1.63 & -1.60 & 2.18 & 4.36 & 3.56 & -41.30 & 1.76 & -6.78 \\
\hline 2010-2011 & -0.91 & -1.95 & 1.07 & 2.79 & -3.54 & 5.86 & 0.84 & -4.14 \\
\hline 2011-2012 & -0.48 & -1.69 & 0.99 & 3.01 & -4.02 & -6.39 & 0.96 & -4.43 \\
\hline 2012-2013 & -0.28 & -1.95 & 0.86 & 2.17 & -0.48 & 3.86 & 0.68 & -3.07 \\
\hline 2013-2014 & -0.34 & -0.41 & 0.27 & 0.73 & -0.32 & -0.37 & 0.20 & -1.00 \\
\hline 2014-2015 & -0.48 & -1.56 & 0.75 & 1.66 & -1.43 & 5.89 & 0.69 & -1.99 \\
\hline 2000-2015 & -0.34 & -0.89 & 0.49 & 1.22 & -1.59 & 4.54 & 0.99 & -3.87 \\
\hline
\end{tabular}

As shown in Table 7, using 2000 as a baseline, the elasticities of the Gini coefficient to urban coal proportion and rural income were -0.34 and 0.99 in 2015, respectively, indicating that the widening of urban-rural disparity was not sensitive to both effects, which were the main reasons for the variation in urban and rural residential coal consumption. By contrast, the increase of urban-rural disparity was mostly sensitive to rural energy intensity and rural population, whose elasticities were 4.54 and -3.87 , respectively, both much greater than 1 . It is demonstrated that the 
decline in rural energy intensity and rapid urbanization in the future would help to narrow the gap between urban and rural coal consumption.

Based on the internal relationships between the urban-rural residential coal consumption Gini coefficient and LMDI decomposition effects, this subsection combines the LMDI and Gini coefficient by analyzing the elasticity between them, which is a novel contribution to existing literature.

\section{Conclusions and policy implications}

\subsection{Conclusions}

Coal combustion is a major source of air pollution and carbon dioxide emissions, and the residential sector, in which an apparent urban-rural coal consumption disparity exists, has always been the second-largest source of coal consumption in China. This study uses an expanded approach by combining the calculation of the Gini coefficient with a comprehensive LMDI decomposition method to analyze the urban-rural residential coal consumption disparity in recent years (2000-2015). By introducing the ratio of rural to urban per capita residential coal consumption and combining it with the urbanization rate, this study simplifies the analysis of urban and rural residential coal consumption and reveals their variation trend, which has not been attempted in prior literature. Moreover, since urban and rural residential coal consumption could be decomposed into coal proportion, energy intensity, income, and population effects, which affect the urban-rural residential coal consumption Gini coefficient indirectly, this study analyzes the elasticity of the Gini coefficient to the abovementioned four LMDI decomposition effects as a novel attempt to combine the Gini coefficient and LMDI method.

Based on the empirical analysis, this study not only shows that the urban-rural residential coal consumption Gini coefficient reached nearly 0.42 in 2015 but also reveals that the rural-to-urban per capita coal consumption ratio is the key reason for this rise. Moreover, with complete LMDI decomposition, this study shows that the urban coal proportion effect was the main reason for the decline in urban residential coal consumption, while the rural income effect dominated the growth of rural 
residential coal consumption from 2000 to 2015. Finally, according to the decoupling index and elasticity analysis based on LMDI decomposition effects, it is found that urban and rural residential coal consumption show strong and weak decoupling, respectively, and the variation of the urban-rural gap is more sensitive to changes in rural energy intensity and population.

Furthermore, the conclusions of this study support the energy ladder theory, indicating that, with economic growth, people tend to use cleaner and energy-efficient fuels. Coal, as a type of commercial energy, ranks second in the residential energy ladder, with traditional bioenergy at the bottom and the most advanced energy source at the top. With economic development, people tend to replace traditional bioenergy with coal at the first stage (in rural), and to substitute coal for more advanced energy at the second stage (in urban). According to the LMDI results, the income effect plays the leading role in the first stage, while the proportion effect dominates the second stage. In addition, we conclude that, with residential income growth, residential coal consumption first increases and then decreases, crossing a turning point.

Finally, considering the management of natural resources, we conclude that rural regions are primary locations for coal consumption management, along with the realization of sustainable development goal. There are two strategies to achieve this goal. The first is to consistently reduce residential coal consumption proportion and energy intensity, as per the LMDI results. The second is to raise the per capita income of rural residents to a certain extent, as per the energy ladder theory, since a higher residential income would lead to the consumption of cleaner energy resources.

\subsection{Policy implications}

Based on our conclusions as well as the targets of clean energy, sustainable communities, and climate action, this study offers the following policy implications.

First, China should continue to reduce urban residential coal consumption by specifying the use and users of coal consumption in urban areas. Although residential coal consumption in urban areas has been declining in recent years, there is scope for further reduction from 9.85 million tce in 2015. Specifying the use and users of coal consumption would help to reduce urban residential coal consumption. The concerned 
government departments and institutions should organize related research to specify the characteristics of urban residents who continue to use coal as a household fuel, such as geographic location, living conditions, and income levels. Additional appropriate measures should be implemented to encourage urban residents to use cleaner energy sources and to reduce the coal proportion.

Second, China should undertake many comprehensive actions to control and cut residential coal consumption in rural areas. In the long run, consistently developing the rural economy and increasing rural income is an effective way to reduce rural residential coal consumption according to the energy ladder theory. In the short and medium terms, strengthening government guidance is essential to encourage rural residents to replace coal with cleaner energy. Further concrete policy intervention options for rural residents are elaborated as follows: 1) providing fiscal support for income or price subsidies for cleaner energy; 2) strengthening the investment and management of the rural power network, and controlling electricity costs for basic rural living; 3) guiding rural centralized residence, and improving rural energy infrastructure, such as natural gas pipelines, and central heating facilities; and 4) employing locally selected policies to promote the use of renewable energies, such as wind power and new bioenergy.

Finally, China should promote new patterns of urbanization with low carbonization. Urbanization will encourage more rural residents to migrate to urban areas, which would create greater pressure on the energy supply system in urban areas. Providing clean and efficient energy for urbanization development is essential for a new pattern urbanization with low carbonization. The Chinese government should vigorously develop new energy sources, and increase the proportion of clean and efficiency energy in residential terminal energy consumption.

In addition, the management of natural resources for sustainable development goals has been equally important for the BRICS group, comprising Brazil, Russia, India, China, and South Africa. China, as one of the important BRICS members, shares some commonalities with the other members, but also has its own particularities. Future research could analyze consumption trends in Brazil, Russia, 
India, and South Africa. For example, India, which ranks as the world's sixth largest energy consumer with the fourth largest coal reserves (Pandey et al., 2011), has faced increasing energy consumption needs along with its economic growth. Further research could focus on these issues.

\section{Acknowledgments}

We appreciate the support of the Program for Major Projects in Philosophy and Social Science Research of the Ministry of Education of China (No. 14JZD031), Key Program of National Social Science Fund of China (No. 15AJY005), National Natural Science Foundation of China (Nos. 71473203, 71171001, and 71471001), and New Century Excellent Talents in University (No. NCET-12-0595).

\section{References}

Achão, C., Schaeffer, R., 2009. Decomposition analysis of the variations in residential electricity consumption in Brazil for the 1980-2007 period: measuring the activity, intensity and structure effects. Energy Policy 37, 5208-5220.

Ang, B.W., 2004. Decomposition analysis for policymaking in energy: which is the preferred method? Energy Policy 32, 1131-1139.

Ang B.W., 2015. LMDI decomposition approach: a guide for implementation. Energy Policy 86, 233-238.

Ang, B.W., Liu, N., 2007. Handling zero values in the logarithmic mean Divisia index decomposition approach. Energy Policy 35, 238-246.

Auffhammer, M., Wolfram, C., 2014. Powering up China: income distributions and residential electricity consumption. Am. Econ. Rev. Pap. Proc. 104, 575-580.

Bhattacharya, M., Rafiq, S., Bhattacharya, S., 2015. The role of technology on the dynamics of coal consumption-economic growth: new evidence from China. Appl. Energy 154, 686-695.

Cai, J., Jiang, Z., 2008. Changing of energy consumption patterns from rural households to urban households in China: an example from Shaanxi Province, China. Renew. Sustain. Energy Rev. 12, 1667-1680. 
Chotikapanich, D., Griffiths, W., 2001. On calculation of the extended Gini Coefficient. Rev. Income Wealth 47, 541-547.

Dai, H., Masui, T., Matsuoka, Y., Fujimori, S., 2012. The impacts of China's household consumption expenditure patterns on energy demand and carbon emissions towards 2050. Energy Policy 50, 736-750.

Diakoulaki, D., Mandaraka, M., 2007. Decomposition analysis for assessing the progress in decoupling industrial growth from $\mathrm{CO} 2$ emissions in the EU manufacturing sector. Energy Econ. 29, 636-664.

Du, L., Guo, J., Wei, C., 2017. Impact of information feedback on residential electricity demand in China. Resour. Conserv. Recycl. 125, 324-334.

Fan, J.L., Liao, H., Liang, Q.M., Tatano, H., Liu, C.F., Wei, Y.M., 2013. Residential carbon emission evolutions in urban-rural divided China: an end-use and behavior analysis. Appl. Energy 101, 323-332.

Fernandez, E., Saini, R.P., Devadas, V., 2005. Relative inequality in energy resource consumption: a case of Kanvashram village, Pauri Garhwal district, Uttaranchal (India). Renew. Energy 30, 763-772.

Geng, C., Wang, K., Wang, W., Chen, J.H., Liu, X.Y., Liu, H., 2012. Smog chamber study on the evolution of fume from residential coal combustion. J. Environ. Sci. 24, $169-176$.

Hosier, R.H., Dowd, J., 1987. Household fuel choice in Zimbabwe: an empirical test of the energy ladder hypothesis. Resour. Energy 9, 347-361.

Jafari, M., Cao, S.C., Jung, J.W., 2017. Geological $\mathrm{CO}_{2}$ sequestration in saline aquifers: omplication on potential solutions of China's power sector. Resour. Conserv. Recycl. 121, 137-155.

Li, J., Hu, S., 2017. History and future of the coal and coal chemical industry in China. Resour. Conserv. Recycl. 124, 13-24.

Liang, L., Wu, W., Lal, R., Guo, Y., 2013. Structural change and carbon emission of rural household energy consumption in Huantai, northern China. Renew. Sustain. Energy Rev. 28, 767-776.

Lin, T., Zhuang, J., Yarcia, D., Lin, F., 2008. Income inequality in the People's 
Republic of China and its decomposition: 1990-2004. Asian Dev. Rev. 25, $119-136$.

Lu, Q., Yang, X., Chuai, X., Wu, C., 2015. Multi-sectoral decomposition in decoupling industrial growth carbon emissions in the developed Jiangsu Province, China. Energy 82, 414-425.

Mukherjee, A.B., Zevenhoven, R., Bhattacharya, P., Sajwan, K.S., Kikuchi, R., 2008. Mercury flow via coal and coal utilization by-products: a global perspective. Resour. Conserv. Recycl. 52, 571-591.

Nie, H., Kemp, R., 2014. Index decomposition analysis of residential energy consumption in China: 2002-2010. Appl. Energy 121, 10-19.

Nilsson, A., Stoll, P., Brandt, N., 2017. Assessing the impact of real-time price visualization on residential electricity consumption, costs, and carbon emissions. Resour. Conserv. Recycl. 124, 152-161.

Niu, S., Zhang, X., Zhao, C., Niu, Y., 2012. Variations in energy consumption and survival status between rural and urban households: a case study of the Western Loess Plateau, China. Energy Policy 49, 515-527.

Pandey, V.C., Singh, J.S., Singh, R.P., Singh, N., Yunus, M., 2011. Arsenic hazards in coal fly ash and its fate in Indian scenario. Resour. Conserv. Recycl. 55, 819-835.

Papathanasopoulou, E., Jackson, T., 2009. Measuring fossil resource inequality-a case study for the UK between 1968 and 2000. Ecol. Econ. 68, 1213-1225.

Sen, A.K., 1997. On Economic Inequality. Clarendon Press, Oxford.

Singh, M., Siddique, R., 2013. Effect of coal bottom ash as partial replacement of sand on properties of concrete. Resour. Conserv. Recycl. 72, 20-32.

Son, H., Kim, C., 2017. Short-term forecasting of electricity demand for the residential sector using weather and social variables. Resour. Conserv. Recycl. 123, 200-207.

Song, M.L., Wang, J.L., Zhao, J.J., 2016. Coal endowment, resource curse, and high coal-consuming industries location: analysis based on large-scale data. Resour. Conserv. Recycl., https://doi.org/10.1016/j.resconrec.2016.08.005. 
Sun, C.W., Ouyang, X.L., 2016. Price and expenditure elasticities of residential energy demand during urbanization: an empirical analysis based on the household-level survey data in China. Energy Policy 88, 56-63.

Sun, D., Fang, J., Sun, J.Q., 2016. Health-related benefits of air quality improvement from coal control in China: Evidence from the Jing-Jin-Ji region. Resour. Conserv. Recycl., https://doi.org/10.1016/j.resconrec.2016.09.021.

Sun, T., Zhang, H.W., Wang, Y., Meng, X.M., Wang, C.W., 2010. The application of environmental Gini coefficient (EGC) in allocating wastewater discharge permit: the case study of watershed total mass control in Tianjin, China. Resour. Conserv. Recycl. 54, 601-608.

Tseng, M.L., Tan, K.H., Geng, Y., Govindan, K., 2016. Sustainable consumption and production in emerging markets. Int. J. Prod. Econ. 181, 257-261.

Van Ruijven, B., Urban, F., Benders, R.M.J., Moll, H.C., Sluijs, J.P.V.D., De Vries, B., Van Vuuren, D.P., 2008. Modeling energy and development: an evaluation of models and concepts. World Dev. 36, 2801-2821.

Wang, Z., Yang, L., 2014. Indirect carbon emissions in household consumption: evidence from the urban and rural area in China. J. Clean. Prod. 78, 94-103.

Yang, X., Teng, F., 2016. The air quality co-benefit of coal control strategy in China. Resour. Conserv. Recycl., https://doi.org/10.1016/j.resconrec.2016.08.011.

Yao, C.S., Chen, C.Y., Li, M., 2012. Analysis of rural residential energy consumption and corresponding carbon emissions in China. Energy Policy 41, 445-450.

Zha, D.L., Zhou, D.Q., Zhou, P., 2010. Driving forces of residential CO2 emission in urban and rural China: an index decomposition analysis. Energy Policy 38, $3377-3383$.

Zhang, J., Kotani, K., 2012. The determinants of household energy demand in rural Beijing: can environmentally friendly technologies be effective? Energy Econ. 34, $381-388$.

Zhang, M., Bai, C.Y., Zhou, M., 2016. Decomposition analysis for assessing the progress in decoupling relationship between coal consumption and economic growth in China. Resour. Conserv. Recycl., 
https://doi.org/10.1016/j.resconrec.2016.06.021.

Zhang, M., Guo, F., 2013. Analysis of rural residential commercial energy consumption in China. Energy 52, 222-229.

Zhang, R., Wei, T.Y., Glomsrød, S., Shi, Q.H., 2014. Bioenergy consumption in rural China: evidence from a survey in three provinces. Energy Policy75, 136-145.

Zhao, C.S., Niu, S.W., Zhang, X., 2012a. Effects of household energy consumption on environment and its influence factors in rural and urban areas. Energy Proced. $14,805-811$.

Zhao, X., Li, N., Ma, C., 2012b. Residential energy consumption in urban China: a decomposition analysis. Energy Policy 41, 644-653.

Zheng, X., Wei, C., Qin, P., Guo, J., Yu, Y.H., Song, F., Chen, Z., 2014. Characteristics of residential energy consumption in China: findings from a household survey. Energy Policy 75, 126-135.

Zhou, S., Teng, F., 2013. Estimation of urban residential electricity demand in China using household survey data. Energy Policy 61, 394-402. 


\section{Appendix A}

The calculation method for urban-rural residential coal consumption is shown in Fig. A.1:

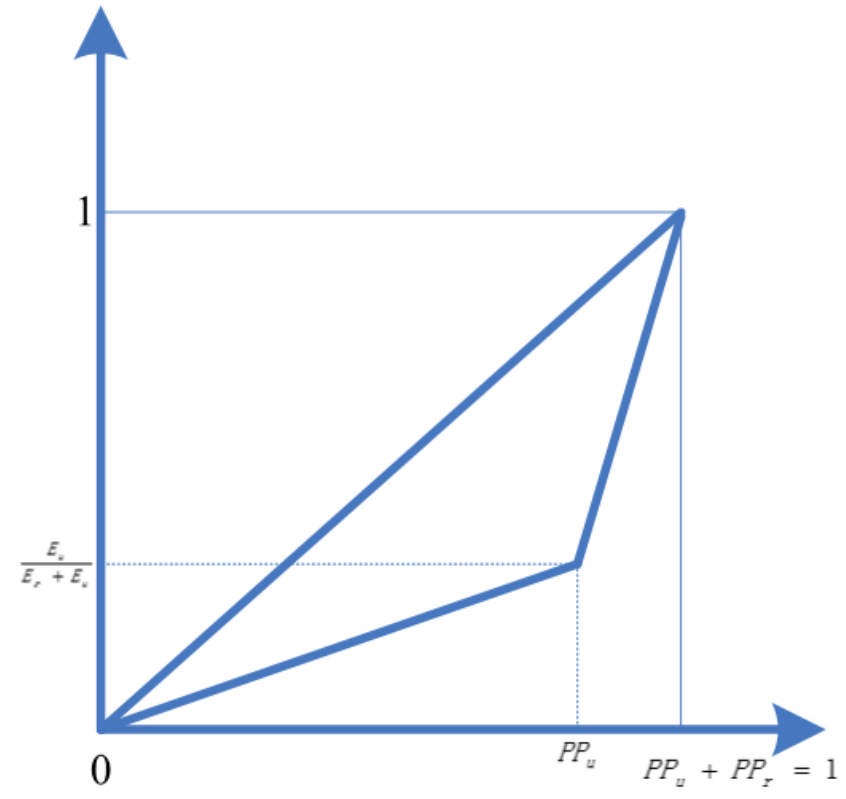

Fig. A.1.

Lorenz Curve and urban-rural Gini coefficient of residential coal consumption.

$$
\begin{aligned}
& G_{u r}=2 \times\left\{\frac{1}{2}-\left[\frac{1}{2} \times P P_{u} \times \frac{E_{u}}{E_{u}+E_{r}}+\frac{1}{2} \times\left(\frac{E_{u}}{E_{u}+E_{r}}+1\right) \times P P_{r}\right]\right\} \\
& =P P_{u}-\frac{E_{u}}{E_{u}+E_{r}}=\frac{E_{r}}{E_{u}+E_{r}}-P P_{r} \\
& =\frac{(e-1) \times P P_{u} \times\left(1-P P_{u}\right)}{(e-1) \times\left(1-P P_{u}\right)+1}
\end{aligned}
$$

$G_{u r}$ represents the urban-rural residential coal consumption Gini coefficient, $E_{u}$

and $E_{r}$ represent aggregate coal consumption by urban and rural residents, respectively; $P P_{u}$ and $P P_{r}$ represent urban and rural population proportion, respectively; and $e$ represents the ratio of rural-to-urban per capita coal consumption.

\section{Appendix B}

According to formulas (2)-(3), $E\left(G_{u r}, e\right)$ and $E\left(G_{u r}, P P_{u}\right)$ can be expressed as follows: 


$$
\begin{aligned}
& E\left(G_{u r}, e\right)=\frac{\partial G_{u r}}{\partial e} \times \frac{e}{G_{u r}} \\
& =\frac{P P_{u} \times\left(1-P P_{u}\right)}{A^{2}} \times \frac{e \times A}{(e-1) \times P P_{u} \times\left(1-P P_{u}\right)} \\
& =\frac{e}{A \times(e-1)} \\
& E\left(G_{u r}, P P_{u}\right)=\frac{\partial G_{u r}}{\partial P P_{u}} \times \frac{P P_{u}}{G_{u r}} \\
& =\frac{A^{2}-e}{A^{2}} \times \frac{P P_{u} \times A}{(e-1) \times P P_{u} \times\left(1-P P_{u}\right)} \\
& =\frac{A^{2}-e}{A \times\left(1-P P_{u}\right) \times(e-1)}
\end{aligned}
$$

where $A=(e-1) \times\left(1-P P_{u}\right)+1$

Combining formulas (B.1) and (B.2) yields formula (4) as follows:

$$
\begin{aligned}
& R=\frac{E\left(G_{u r}, e\right)}{E\left(G_{u r}, P P_{u}\right)} \\
& =\frac{e}{A \times(e-1)} \times \frac{A \times\left(1-P P_{u}\right) \times(e-1)}{A^{2}-e} \\
& =\frac{e \times\left(1-P P_{u}\right)}{\left[(e-1) \times\left(1-P P_{u}\right)+1\right]^{2}-e}
\end{aligned}
$$

